\title{
Syringomyelia associated with inappropriate antidiuretic hormone secretion
}

\author{
Paula Barros Alcalde, Arturo González Quintela, Marta Pena Seijo, Antonio Pose-Reino
}

Department of Internal Medicine, Complexo Hospitalario Universitario de Santiago de Compostela, Santiago de Compostela, La Coruña, Spain

\section{Correspondence to} Professor Antonio Pose, antonio.pose.reino@sergas.es

Accepted 19 March 2014

\section{CrossMark}

\footnotetext{
To cite: Barros Alcalde $P$, González Quintela A, Pena Seijo M, et al. BMJ Case Rep Published online: [please include Day Month Year] doi:10.1136/bcr-2013202575
}

\begin{abstract}
SUMMARY
Hyponatraemia is the most common fluid-electrolyte disorder, and the most frequent related aetiologies are syndrome of inappropriate secretion of antidiuretic hormone (SIADH), which accounts for up to $38 \%$. SIADH has been linked to multiple pathologies that affect the central nervous system; these disorders generally originate in the brain and, more rarely, in the spinal cord. It is often observed in patients undergoing neurosurgery and in patients with head injuries or intracranial tumours, and less common in those with spinal pathologies, especially traumatic. We describe an SIADH case associated with syringomyelia, in a patient admitted for severe, symptomatic hyponatraemia.
\end{abstract}

\section{BACKGROUND}

The syndrome of inappropriate secretion of antidiuretic hormone (SIADH) is defined by the presence of hypotonic hyponatraemia in a context of inadequately diluted urine and hipo-osmolality in plasma, with normal circulating volume and after excluding renal failure, adrenal insufficiency, severe hypothyroidism, drugs and physiological stimuli of $\mathrm{ADH}$ secretion. SIADH has been found to be one of the most frequent causes of hyponatraemia in the hospitalised patient.

Most SIADH are diagnosed as idiopathic and later a causal process is found, often a neoplastic process. To diagnose idiopathic SIADH, an exhaustive study is needed to discard other causes and even so, the patient should be strictly watched, for the next few years. In our patient, we found syringomyelia as a cause of SIADH after a rigorous study and after discarding other aetiologies of euvolaemic hypo-osmolality. As far as we know, this is the first case described in the literature of a chronic SIADH case related with syringomyelia.

\section{CASE PRESENTATION}

A 62-year-old hypertensive woman with type 2 diabetes, anxious-depressive syndrome and rheumatoid arthritis was treated with Metilprednisolona $1 \mathrm{mg}$ a day. The patient had generalised weakness, asthenia, nausea, unsteady gait and anorexia that started approximately 1 month ago. As laboratory tests made at her health centre revealed severe hyponatraemia, she was referred to our department. Hyponatraemia already appeared in previous inspections carried out since 2008, although the figures corresponded to mild hyponatraemia (serum sodium between 130 and $135 \mathrm{mEq} / \mathrm{L})$.

When the patient was admitted to the hospital, she had serum sodium $116 \mathrm{mEq} / \mathrm{L}$, serum potassium $4.5 \mathrm{mEq} / \mathrm{L}$, plasma osmolarity $273 \mathrm{mOsm} / \mathrm{L}$, urine osmolarity $415 \mathrm{mOsm} / \mathrm{L}$, urinary sodium $37 \mathrm{mEq} / \mathrm{L}$ and urinary potassium $15 \mathrm{mEq} / \mathrm{L}$. Creatinine levels and blood urea concentration were normal. There were no signs of hypovolaemia like blood pressure decrease by orthostatic tachycardia or decreased skin turgor and dry mucous. There were no signs of hypervolaemia (ascites, oedema) either. We concluded, therefore, that the patient was euvolaemic.

Thyroid hormones were normal. We have determined cortisol and adrenocorticotropic hormone to discard adrenal insufficiency and we obtained normal values, so we discarded other causes of euvolaemic hypo-osmolality different SIADH. Furthermore plasma renin values were slightly high, with normal aldosterone, uric acid $4 \mathrm{mg} / \mathrm{dL}$ and inappropriately high vasopressin levels regarding natraemia and osmolarity carried out at that moment (vasopressin: $1.3 \mathrm{pg} / \mathrm{mL}$, with plasma sodium: $131 \mathrm{mEq} / \mathrm{L}$ and plasma osmolarity: $285 \mathrm{mOsm} / \mathrm{L}$ ).

There was no antecedent of cranial trauma, and brain, chest and abdominal CT scans were carried out, discarding ongoing neoformative disease and confirming SIADH diagnosis.

During admission, impaired thermal sensitivity was observed in arms and shoulders on a rigorous neurological examination, although tactile sensitivity remained normal. Brain and spinal cord NMR scans were therefore requested, revealing the presence of an intramedullary cavity affecting the spinal cord to approximately D9, not associated with Chiari malformation (figure 1).

\section{TREATMENT}

After withdrawing concomitant drugs that could cause hyponatraemia (such as escitalopram, olmesartan and hydroclorothiazide), hypertonic saline (3\%) was started $(0.5 \mathrm{~mL} / \mathrm{kg} / \mathrm{h})$, and it was stopped once serum sodium level had increased above $120 \mathrm{mEq} / \mathrm{L}$.

Once the serum sodium achieved normal levels (more than $135 \mathrm{mEq} / \mathrm{L}$ ), the patient was discharged, but in subsequent checkups hyponatraemia reappeared. Given the difficulty that fluid restriction entailed for the patient, and whereas natraemia was less than Natriuria plus Kaliuria, treatment was instigated with Tolvaptan $15 \mathrm{mg} /$ day, achieving adequate serum sodium control a few days later, so it was decided to reduce the dose gradually under supervision to $15 \mathrm{mg}$ twice weekly.

\section{OUTCOME AND FOLLOW-UP}

After treatment adequate serum sodium control has been observed on an outpatient basis, without any other symptoms that could justify SIADH in more than 12 months of follow-up. 


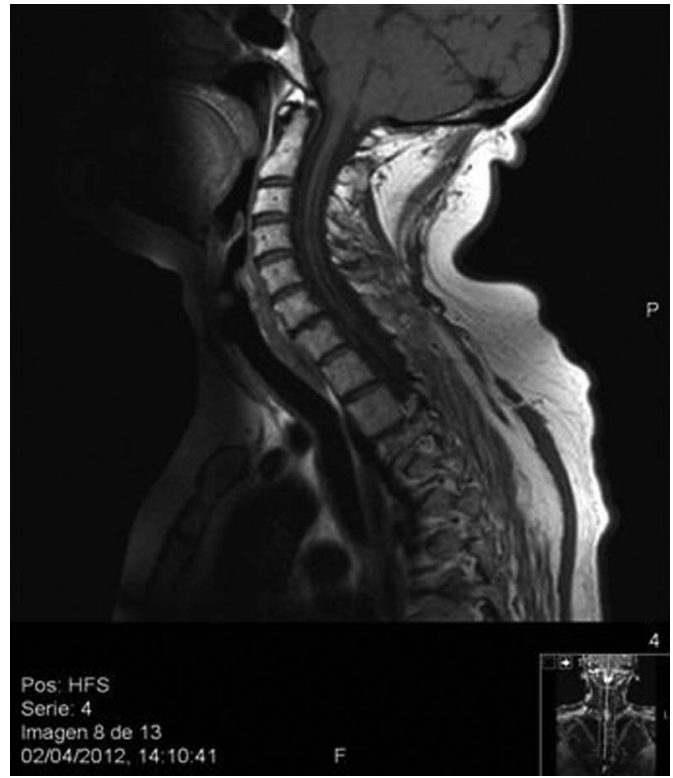

Figure 1 Brain and spinal cord NMR scan showing the presence of an intramedullary cavity affecting the spinal cord to approximately D9, not associated with Chiari malformation.

\section{DISCUSSION}

Hyponatraemia association with intracranial diseases is well documented, less frequently reported is the association of transient SIADH and spinal injuries. ${ }^{1}$ This is the case of spinal fusion in patients with severe scoliosis or spondylolisthesis, who suffer SIADH postsurgery. ${ }^{2}$ Hyponatraemia can develop after any type of surgery and more commonly in brain or spinal cord surgery, which is the case of surgery with spinal or epidural anaesthesia. Frisbie $^{3}$ reported that higher levels of spinal injury were more often associated with hyponatraemia, while Peruzzi et al ${ }^{4}$ suggested that the most important predictor for hyponatraemia development is the spinal injury type.

Thus, a Frankel class A injury, with loss of sensitivity and strength below the lesion, is more often associated with hyponatraemia than a class E injury, without loss of either sensitivity or strength. ${ }^{4}$

Our patient had syringomyelia, with a cavity from the cervical spine to D9. Furlan and Fehlings ${ }^{5}$ postulated a specific, multifactorial cause for hyponatraemia following spinal cord injury, among which could be impairment of the descending renal sympathetic fibres, responsible for renal water and sodium retention, mediated by renin release; which does not seem to be the most accurate hypothesis, since the values of plasma renin levels are normal or even slightly high.

Presence of potentially causal neurological diseases does not always imply responsibility for clinical condition; in fact, there are injuries rarely associated with the syndrome, and therefore screening should be performed for other potentially serious causes that could be responsible, such as neoplasia. In our case screening was carried out and no other possible SIADH cause was found. However, given that SIADH aetiology can be multifactorial, other intercurrent factors should also be taken into account, such as drugs, intravenous fluids and also various osmoregulatory mechanisms that influence antidiuretic hormone secretion. After drugs discontinuation, symptoms appeared again, meaning that syringomyelia was causing the syndrome.

After hypertonic saline, when levels of natraemia are more than $120 \mathrm{mEq} / \mathrm{L}$, the treatment of choice for SIADH is, when possible, fluid restriction. This usually happens in reversible situations, being more difficult to maintain for long periods of time due to the persistence of thirst reflex, as well as patient's comorbidities that often make it unfeasible. In addition, in situations where urinary sodium plus potassium is higher than serum sodium (Furst formula ${ }^{6}$ ) fluid restriction does not operate.

In our case, it was decided to initiate an oral selective arginine vasopressin V2 receptor antagonist Tolvaptan, at a dose of $15 \mathrm{mg} /$ day. Later, it was possible to reduce the dose to $15 \mathrm{mg}$ twice weekly, a dose lower than that currently recommended for management of chronic SIADH. ${ }^{7}$

In summary, we present an SIADH case associated with cervicodorsal syringomyelia, which debuted with clinically severe symptomatic hyponatraemia, and which responded effectively and was maintained at a low Tolvaptan dose. This is the first syringomyelia case described associated with chronic SIADH.

\section{Learning points}

- Hyponatraemia is the most common fluid-electrolyte disorder (over $30 \%$ of hospitalised patients), and syndrome of inappropriate secretion of antidiuretic hormone (SIADH) is one of the most frequent causes.

- SIADH is caused by multiple aetiologies. To diagnose idiopathic SIADH, an exhaustive study is needed to discard other causes, and even so, the patient should be strictly observed, during the next few years.

- After fluid restriction or when fluid restriction is not adequated, vaptans are the unique and effective therapeutic option.

\section{Competing interests None.}

\section{Patient consent Obtained.}

Provenance and peer review Not commissioned; externally peer reviewed.

\section{REFERENCES}

1 Sherlock M, O'Sullivan E, Agha A, et al. Incidence and pathophysiology of severe hyponatraemia in neurosurgical patients. Postgrad Med J 2009;85:171-5.

2 Bell GR, Gurd AR, Orlowski JP, et al. The syndrome of inappropriate antidiuretic-hormone secretion following spinal fusion. J Bone Joint Surg Am 1986;68:720-4.

3 Frisbie JH. Salt wasting, hypotension, polydipsia, and hyponatremia and the level of spinal cord injury. Spinal Cord 2007;45:563-8.

4 Peruzzi WT, Shapiro BA, Meyer PR Jr, et al. Hyponatremia in acute spinal cord injury. Crit Care Med 1994;22:252-8.

5 Furlan JC, Fehlings MG. Hyponatremia in the acute stage after traumatic cervical spinal cord injury: clinical and neuroanatomic evidence for autonomic dysfunction. Spine 2009;34:501-11.

6 Furst H, Hallows KR, Post J, et al. Am J Med Sci 2000;319:240-4.

7 Runkle I, Villabona C, Navarro A, et al. The treatment of hyponatremia induced by the syndrome of inappropriate antidiuretic hormone secretion (SIADH) a multidisciplinary Spanish algorithm. Med Clin (Barc) 2013;141:507.e1-507.e10. 
Copyright 2014 BMJ Publishing Group. All rights reserved. For permission to reuse any of this content visit http://group.bmj.com/group/rights-licensing/permissions.

BMJ Case Report Fellows may re-use this article for personal use and teaching without any further permission.

Become a Fellow of BMJ Case Reports today and you can:

- Submit as many cases as you like

- Enjoy fast sympathetic peer review and rapid publication of accepted articles

- Access all the published articles

- Re-use any of the published material for personal use and teaching without further permission

For information on Institutional Fellowships contact consortiasales@bmjgroup.com

Visit casereports.bmj.com for more articles like this and to become a Fellow 